\title{
Enhancing English as a Second Language Learners' Speaking Skills through Authentic Videoconferencing
}

\author{
Sharifah Kuraisya Syed Ibrahim, Harwati Hashim \\ Faculty of Education, National University of Malaysia, Bandar Baru Bangi, Malaysia \\ Email: harwati@ukm.edu.my
}

How to cite this paper: Ibrahim, S. K. S., \& Hashim, H. (2021). Enhancing English as a Second Language Learners' Speaking Skills through Authentic Videoconferencing. Creative Education, 12, 545-556. https://doi.org/10.4236/ce.2021.123037

Received: January 31, 2021

Accepted: March 6, 2021

Published: March 9, 2021

Copyright (c) 2021 by author(s) and Scientific Research Publishing Inc. This work is licensed under the Creative Commons Attribution International License (CC BY 4.0).

http://creativecommons.org/licenses/by/4.0/

\section{(c) (i) Open Access}

\begin{abstract}
The concern over speaking skills being abandoned in English as a Second Language (ESL) classroom has been emphasised on for decades yet not much has changed in the past years. With the increasing reliance on technology, authentic videoconferencing, which is now possible with the emergence of various videoconferencing platforms, is believed to be supportive of ESL learners' development in terms of their speaking skills. This paper reviews past studies done on the effects of authentic videoconferencing on ESL students' English-speaking skills. Based on the data gathered, it has been found that ESL learners' speaking skills which include fluency, accuracy, pronunciation and vocabulary can be positively affected with the penultimate and the last skills both showing more promising results. This paper also discusses the individual factors that may either impede or ease ESL learners' development of oral competence. These individual factors include anxiety, enjoyment and class level. The data collected show erratic results with regard to enjoyment and class level whereas anxiety is allegedly able to negatively impact learners' progress. The findings gathered in this paper could serve as a springboard for authentic videoconferencing to be made accessible in ESL classrooms especially in Malaysia to ensure learners' vast improvement as well as engagement in the target language.
\end{abstract}

\section{Keywords}

English as a Second Language (ESL), Speaking Skills, Authentic Videoconferencing

\section{Introduction}

Among the four English as a Second Language (ESL) skill, speaking is the 
most crucial in learning a second language yet ironically, it is the most neglected skill as ESL teachers often resort to drilling and memorisation in teaching speaking skills (Bahadorfar \& Omidvar, 2014; Dewi et al., 2016; Rao, 2019). As English is a global language which enables people from different countries to communicate, it is essential that more platforms of communication are established for Non-Native Speakers (NNS) of English who are either ESL or English as a Foreign Language (EFL) learner to interact with Native Speakers (NS).

Technology has become part and parcel of education for decades and the use of technology is now synonym with the teaching and learning of ESL around the globe (Ahmadi, 2018). Among the positive impacts brought by technology alongside its capability of improving the process of teaching and learning as well as its ability to hinder geographical restriction, is its nature of accommodating globalisation through videoconferencing which enables students to communicate with their peers coming from other parts of the country (Raja \& Nagasubramani, 2018). This has been made possible through the invention of various online applications which have now allowed authentic videoconferencing to be part of ESL teaching.

As technology is utilised via the use of computer and internet, learners develop higher order thinking skills and it can be clinched that multimedia combined with teaching methodology, is crucial to entice learners towards English language learning (Ahmadi, 2018). Until recently, it would have been common for educators and educational designers to refer to teaching as a process that can be categorically divided into two branches namely face-to-face and online but today, these two domains offer further options to learners and educators (Kessler, 2018) and videoconferencing is part of the latter domain.

The term online can be further divided into two categories which are synchronous and asynchronous. Videoconferencing falls directly under synchronous learning as according to Kessler (2018) communication done through the use of synchronous tools is similar to face-to-face communication and involves technology like texting, chats as well as microblogging as opposed to asynchronous interaction which is done through turn-taking over a period of time. In ESL teaching and learning, students can improve speaking skills via the use of numerous applications to have online conferences which enable them to interact with friends, other students, teachers and also NS which can ultimately boost their intercultural awareness, motivation and level of interaction (Bahadorfar \& Omidvar, 2014). This supports the notion that authentic videoconferencing can somewhat assist in the development of ESL learners' speaking skills.

However, in public schools in Malaysia, the access to authentic videoconferencing is still not available as part of the classroom language instruction and activity. Blake (2013) affirmed that ESL learners will have the ability to develop pragmatic and sociolinguistic competence through face-to-face interaction with NS specifically if it takes place in the native country. Hiring teachers who are NS or sending students abroad for the sake of such exposure is a much costlier op- 
tion in comparison to providing a platform for ESL students to communicate with NS on a weekly basis. Thus, this paper aims to review studies done on the effects of authentic videoconferencing on ESL students' English-speaking skills and to discuss the individual factors that contribute to ESL students' English-speaking ability with the hope that it could shed some light on how ESL learners' speaking skills could be positively affected through authentic videoconferencing.

In this paper, the term "authentic videoconferencing" will first be addressed with regard to its definition, strengths and weaknesses. In the following section, four subsections which represent different speaking skills will point out the success or failure of such method in ESL classrooms through results obtained from past studies. Following this, another section is dedicated on individual factors that may or may not impact ESL learners' progress with the implementation of authentic videoconferencing in classroom. Finally, some pedagogical implications will be laid out to demonstrate how such method of teaching may positively benefit ESL learners.

\section{Authentic Videoconferencing}

Ritzel (2010) defines videoconferencing as "an interactive tool that that incorporates audio, video, computing, and communications technologies to allow people in different locations to collaborate face-to-face, in real time, and share all types of information including data, documents, sound and picture" (p. 62). The word "authentic" addresses the nature of the conversation which will be taking place among ESL learners with the NS of English. Thus, authentic videoconferencing could easily be seen as a platform for ESL learners to get the oral exposure needed to enhance their speaking skills despite coming from various parts of the globe.

The need for authentic videoconferencing among ESL learners is not to portray the idea that non-native speaking English teachers are any less of a teacher compared to NS. In a study done by Atamturk et al. (2018) on EFL learners in Turki, it was found that the participants' main interest was to have English teachers whose teaching skills are good regardless of the NS or NNS status. Another study done much earlier by Mahboob (2004) to investigate ESL learners' preferences with regard to NS or NNS English teachers reported that learners highlighted both positive and negative qualities of NS and NNS teachers in terms of linguistic factors, teaching styles and personal factors. To be more precise, this paper is not written to generate the idea that NS who do not specialise in the education field can be better teachers to ESL learners than NNS teachers whose area of expertise is ESL teaching. Instead, it is to verify the idea that occasional exposure to NS may be of aid in developing ESL learners' speaking skills.

Authentic videoconferencing may generally benefit ESL learners in several ways. Skype, a platform used for videoconferencing, enables learners to communicate orally with their counterparts and benefit in second language learning by 
having the ability to increase the communication speed in the target language and eventually become more inspired to learn and speak fluently (Mustafa, 2018). Participants of videoconference are offered the opportunity to observe the body language, facial expressions and other non-verbal cues (Ritzel, 2010) and this is rather helpful in the process of learning as opposed to a traditional phone call. When used in classroom, videoconferencing also offers learners the chance to "go" on virtual field trips while communicating with participants from other locations, accommodates diverse learning styles and provokes learners' interests through the utilisation of video clips, graphics and animation (Ritzel, 2010).

Notwithstanding the countless amounts of benefits, there are always two sides of the same coin. When learners' audio channel fails to function, the chat function has to be used as a back-up (Hampel \& Stickler, 2012) and this as a result, contradicts the whole purpose of conducting the videoconference session. Hampel and Stickler (2012) also claimed that the nature of videoconferencing which only allows one person to speak at a time may hamper interaction as turn-taking is largely affected leading to possible interruptions. Some technological aspects namely time delay, background noises and other technical complications were seen as downsides and to add to that, there is also a challenge in establishing effective interaction and relationship from afar (Gillies, 2008). In Malaysia, despite schools having access to internet connection, the speed and connectivity are still at a discouraging level and at times teachers resort to using their personal internet connection to ensure smooth connection during a videoconferencing session (Abd Halim et al., 2018).

Videoconferencing has its own strengths and shortcomings. Despite the presence of the latter, a myriad of applications and websites have been developed for the purpose of connecting people. These include Zoom, Google Meet, Cisco Webex, Microsoft Teams and heaps more applications whose names have been skyrocketing of late. With the presence of these sites and applications, authentic videoconferencing has been made possible even for those in remote areas as long as they have access to stable internet connection.

\section{Authentic Videoconferencing in Enhancing ESL Students' Speaking Skills}

In this section, the impacts of videoconferencing on four crucial speaking skills namely fluency, accuracy, pronunciation and vocabulary will be discussed and the arguments will be supported by numerous past studies that focused primarily on the use of authentic videoconferencing to enhance learners' language ability.

\subsection{Fluency}

"The basic measures of fluency are the rates (in time) of the production of spoken linguistic units, like words per minute" (Bernstein et al., 2010: p. 1241). Five metrics of fluency have been identified by Hirotani et al. (2012) in their study to 
observe the fluency of learners studying Japanese as a Foreign Language (JFL) and these factors include the number of syllables spoken, the number of pauses, the speech rate number of syllables spoken per second, the articulation rate number of syllables per phonation time, and the Average Syllable Duration (ASD) - speaking time per syllable (Spring et al., 2019).

In their study to investigate the effects of authentic videoconferencing on JFL learners, Spring et al. (2019) concluded that there were significant differences in the number of syllables spoken and the number of pauses while speech rate, articulation rate and ASD showed no significant differences in the pre-test and post-test. This demonstrates that despite participants having spoken more in the post-test, they also paused more which has developed an ambiguity as to whether they became more fluent. However, the time spent engaging in an authentic videoconference was revealed to have positively affected some measures of fluency. Overall, it was concluded by the researchers that participants' ability to dominate by speaking for more than $50 \%$ in the target language in an authentic videoconference will eventually result in fewer pauses. Although this study was conducted on JFL learners, it can be associated with ESL learners as both languages are considered foreign to these learners.

Nilayon and Brahmakasikara (2018) conducted an almost similar study except on EFL students in a private university in Bangkok in which learners were assessed by an IELTS examiner prior to having authentic videoconference and again after. It was clinched that authentic videoconferencing can somewhat improve most of the participants' fluency score especially ones with lower speaking competency from the elementary group. However, this could also be due to the fact that some participants were already good in terms of their EFL fluency. All in all, it could be summarised that ESL learners would largely benefit in terms of fluency if they were given the opportunity to engage in a conversation with NS and this is primarily possible with the existence of videoconferencing.

\subsection{Grammar and Accuracy}

According to Gan (2012) it is reported by some ESL learners that to ensure grammatical accuracy in speaking, they would think of the grammar items involved prior to producing the speech and when they have no time to think they end up making mistakes following their "feel" for correctness. This somewhat demonstrates to us that having no time to think may affect ESL learners' grammar and accuracy but when we look at it from the fluency angle, speakers may sound more fluent despite the mistakes made. Thus, a clear balance has to be obtained between these two subdivisions of speaking skills.

Other than looking at participants' fluency, Nilayon and Brahmakasikara (2018) also paid attention on their grammar and accuracy. Based on the pre-test and post-test results, it was found that half of the participants showed improvement with regard to accuracy with participants from the elementary group again showing the most improvement. This rejects the notion that only competent ESL 
speakers would be able to engage in authentic videoconference as it clearly shows that ESL learners of a lower proficiency level could improve even more provided that they were given the chance.

Nevertheless, a totally opposite finding was gained in a study done by Alshahrani (2016) on EFL learners from Saudi Arabia. In this study which had two groups of participants namely the control and the experiment group, the former group who joined traditional instruction EFL class, showed a much more significant improvement with regard to grammar in the post-test compared to the participants from the experiment group who had videoconference sessions with NS of English. These two contradicting results call for a future study that focuses on the effects of authentic videoconferencing on this particular aspect of speaking skills.

\subsection{Pronunciation}

A lot of past studies have reported that ESL/EFL learners prefer NS English teachers when it comes to teaching pronunciation (see Guerra, 2017; Lasagabaster \& Sierra, 2005; Levis et al., 2017) although they do prefer NNS English teachers for other areas of the language i.e. grammar and strategy training as well as teaching in general i.e. fulfilling students' needs and commitment to teaching. Although as found by Gan (2012) some learners do struggle with inconsistency in pronunciation considering two different streams available i.e. British and American pronunciation for certain words, it is undeniable that being exposed to NS of English is an excellent way of improving ESL learners' pronunciation.

Lu et al. (2014) confirmed this view in their study which involved Chinese pre-service English teachers who had authentic videoconferencing sessions with NS of English. The post-test scores showed that the experiment group landed higher scores than those in the control group on the measure of pronunciation. Similar findings were reported by Alshahrani (2016) as the former group scored higher than those in the latter. Nilayon and Brahmakasikara (2018) also generated the same results in the qualitative study as almost all the participants showed significant improvement in terms of pronunciation based on observation by their NS partners and the IELTS examiner as well as their post-test results. In essence, it ought to be emphasized that this particular aspect of speaking skills shows the most consistent findings and it can be said that ESL students would definitely gain benefits by being exposed to authentic videoconferencing.

\subsection{Vocabulary and Lexical Resource}

Gan (2012) stated that many ESL learners identify insufficient vocabulary as among the factors that affect their fluency in speaking the language as contrary to writing, in speaking, they have less time to think and this occasionally results in them not being able to appropriately express themselves. Lu et al. (2014) concluded that the vocabulary aspect can be tackled through both videoconferencing with NS as well as the traditional method of teaching based on the findings 
gathered from their study in which almost similar results were reported by the experiment and control group with the latter group exceeding the former by just a little.

Nonetheless, EFL learners who participated in the study done by Nilayon and Brahmakasikara (2018) as well as the participants in the experiment group of the study conducted by Alshahrani (2016) showed significant improvement in the vocabulary aspect of the speaking skills. This could be due to the fact that they were gradually exposed to NS of English through authentic videoconferencing. Similar findings were reported by Vurdien (2019) as in the study conducted, participants from the experiment group who were engaged in authentic videoconferencing were reported to have enhanced their vocabulary by incorporating them in their utterances as opposed to the participants in the control group who had insufficient time to do so as it was believed that learning through videoconferencing offers more time for participants to prepare themselves for the interaction especially when the participants are aware of the topics to be discussed. In total, authentic videoconferencing can allegedly enrich ESL learners' vocabulary as they pick up the words and gradually expand their lexical resources by engaging in a conversation with NS of English.

\section{Individual Factors Affecting ESL Learners' Speaking Skills Improvement via Authentic Videoconferencing}

Authentic videoconferencing is hoped to be one of the ways to enhance ESL learners' speaking skills in the target language. However, there are still individual contributing factors that have got to be considered to achieve huge amount of success in incorporating such technique to boost ESL learners' verbal capabilities. Spring et al. (2019) found in her studies that students of the intermediate level who participated in authentic videoconferencing session showed more improvement in comparison with their counterparts from the beginner level. This finding is utterly against the results presented by Nilayon and Brahmakasikara (2018) as it was explained that those of beginner level showed more improvement compared to those of the intermediate level. This proves that class level may or may not be among the contributing individual factors affecting the development of ESL learners' oral competence.

However, ESL learners' level of anxiety may be a determining factor with regard to their improvement in speaking skills. Anxious learners are more prone to avoid answering difficult or personal questions in the target language as their anxiety impacts the communication strategy employed by them in language class (Horwitz et al., 1986). They also introduced three key factors leading learners towards speaking performance anxiety i.e., communication apprehension, test anxiety and fear of negative evaluation. Miskam \& Saidalvi (2018) who implemented a study on Malaysian undergraduates to investigate their level of anxiety in speaking English as well as the main contributing factors towards such issue found that majority of the participants had moderate level of anxiety which is 
equally worrying as having high level of anxiety because even at such level, their English-speaking performance can be stunted. In terms of the key factors, for those with high and moderate level of anxiety, the primary factor bothering them was communication apprehension as they had the fear that they would not be understood by others or they would not be able to comprehend others' questions. Thus, something ought to be done to convince ESL learners to be more confident in speaking English despite their low level of command in the target language.

Enjoyment could also be a defining factor in students speaking skills' development. ESL learners who are engaged in situations where proficient learners tend to dominate may suffer from reduced motivation and higher inclination to avoid speaking due to the disparity in the opportunities provided (Yang et al., 2012). However, Spring et al. (2019) summed up in their study based on the data collected that enjoyment does not heavily impact learners' oral improvement as it was proposed that participants who enjoy the classroom instruction method i.e. authentic videoconferencing may not develop their oral competence very much and likewise, those who do not may somehow improve. Contrarily, Abd Halim et al. (2018) in their study on the use of Skype in primary school classroom found that ESL learners enjoyed learning and communicating with pupils from other schools in Malaysia through Skype and this positively intensified their intrinsic motivation. The learners also requested to have such session with pupils from other countries. However, prior to the project, the researchers who had received requests from foreign schools decided to decline the proposals due to the time difference between countries.

Individual factors such as class level, anxiety and enjoyment may impact the success of authentic videoconferencing in enhancing ESL learners' speaking skills. As shown in Figure 1, class level may either positively impact ESL learners' speaking ability or it may not be the contributing factor at all. Those from higher class level may show more promising improvements as opposed to those from the lower-class level and similarly those from lower class level may enhance their oral competence better than those of the higher-class level. This demonstrates that this particular individual factor does not have a consistent effect. Anxiety, on the other hand, reveals the soundest data as past studies show a strong albeit negative connection between anxiety and learners' oral development. With regard to enjoyment, similar to class level, it may either positively impact learners' oral competence or there may be no linkage at all as learners may purely enjoy the lesson without any notable advancement in the target language. Based on past studies cited above, it is safe to say that ESL learners have to be well-prepared for such change to be brought into the syllabus and some issues will have to be tackled prior to the implementation of this particular teaching technique. Thus, all the contributing factors from all possible angles will have to be analysed and looked into in order to ensure a huge success in incorporating authentic videoconferencing as a method of teaching speaking. 


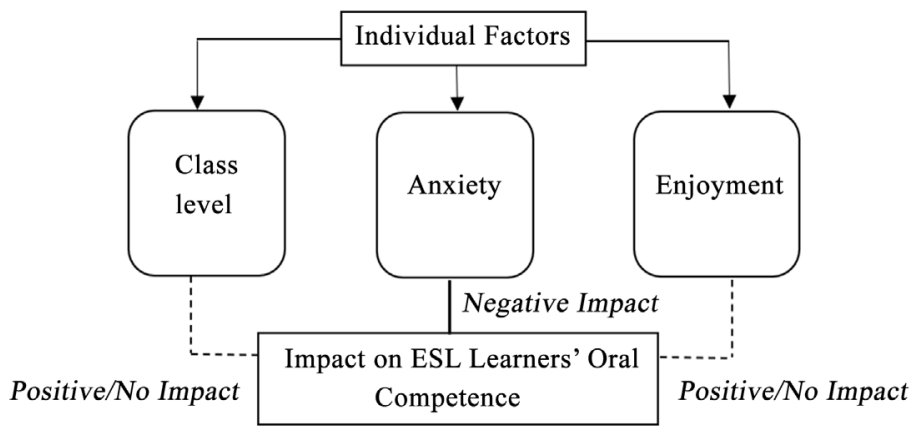

Figure 1. Individual factors affecting ESL learners speaking skill development.

\section{Pedagogical Implications}

As discussed in the preceding sections, there are both strengths and weaknesses of conducting an authentic videoconferencing session. Although, internet stability may hinder the whole process of natural interaction between ESL learners and NS, it is not an obstacle that has no viable solution. More efforts need to be put by school administrators as well as other stakeholders i.e., parents, teachers, parent-teacher association and even students to ensure that learners have access to such exposure which will benefit them greatly since they are likely to enhance their technological literacy apart from their ESL knowledge.

On top of that, there are clearly more advantages compared to disadvantages of authentic videoconferencing on ESL learners' speaking skills. ESL learners get to improve their speaking skills i.e., fluency, accuracy, pronunciation and vocabulary even with occasional exposure to such activity. Nevertheless, if the activity were to be conducted as a group, ESL teachers ought to monitor and encourage learners who are more prone to stay quiet and unwilling to participate in the interaction. Conducting such activity on one-to-one basis may be time consuming and more costly but it is achievable with the cooperation of all stakeholders.

To sum up, authentic videoconferencing will not only enhance ESL learners' speaking skills but it will also provide these learners the exposure they need to intensify their own self-confidence when they engage in a conversation with NS. This prepares learners for the future and helps them carve their career paths with less difficulty as English is a language termed as a lingua franca and highly needed for one's self-development as it assists in communication for various essential purposes.

\section{Conclusion}

Taking everything into account, it is safe to say that authentic videoconferencing, despite its challenging nature due to the internet connectivity and other technical complications, may positively impact ESL learners' speaking skills which include fluency, accuracy, pronunciation as well as vocabulary. Pronunciation and vocabulary can be especially positively impacted as getting exposure to the way NS pronounce words in English and the vast vocabulary they possess, 
will definitely provide huge assistance for ESL learners to develop their oral competence. At the same time, individual factors like class level, anxiety and enjoyment should also be taken into consideration. Authentic videoconferencing helps in diversifying the methods of language, especially ESL teaching and the door has to be opened for such technique to be part of the ESL classroom instruction to provide joy and required exposure for ESL learners to boost their verbal aptitude.

\section{Acknowledgements}

The authors would like to thank Universiti Kebangsaan Malaysia under the Research Grant number 1) GG-2019-077 and 2) GG-2020-027 for supporting this project.

\section{Conflicts of Interest}

The authors declare no conflicts of interest regarding the publication of this paper.

\section{References}

Abd Halim, S. Z. S., Mohamad, M. H., \& Yunus, M. M. (2018). Skype in the Classroom-An Online Collaboration Awareness Campaign to Develop Speaking Skill. International Journal of Innovative Research and Creative Technology, 4, 57-61.

Ahmadi, M. R. (2018). The Use of Technology in English Language Learning. International Journal of Research in English Education, 3, 115-125. https://doi.org/10.29252/ijree.3.2.115

Alshahrani, A. A. (2016). Communicating Authentically: Enhancing EFL Students' Spoken English via Videoconferencing. Computer Assisted Language Learning Electronic Journal, 17, 1-17.

Atamturk, N., Atamturk, H., \& Dimililer, C. (2018). Native Speaker Dichotomy: Stakeholders' Preferences and Perceptions of Native and Non-Native Speaking English Language Teachers. South African Journal of Education, 38, 1-10. https://doi.org/10.15700/saje.v38n1a1384

Bahadorfar, M., \& Omidvar, R. (2014). Technology in Teaching Speaking Skill. Acme International Journal of Multidisciplinary Research, 2, 9-13.

Bernstein, J., Cheng, J., \& Suzuki, M. (2010). Fluency and Structural Complexity as Predictors of L2 Oral Proficiency. 11th Annual Conference of the International Speech Communication Association, Makuhari, September 26-30 2010, 1241-1244.

Blake, R. J. (2013). Brave New Digital Classroom: Technology and Foreign Language Learning. Washington DC: Georgetown University Press.

Dewi, R. S., Kultsum, U., \& Armadi, A. (2016). Using Communicative Games in Improving Students' Speaking Skills. English Language Teaching, 10, 63-71. https://doi.org/10.5539/elt.v10n1p63

Gan, Z. (2012). Understanding L2 Speaking Problems: Implications for ESL Curriculum Development in a Teacher Training Institution in Hong Kong. Australian Journal of Teacher Education, 37, 43-59. http://dx.doi.org/10.14221/ajte.2012v37n1.4

Gillies, D. (2008). Student Perspectives on Videoconferencing in Teacher Education at a Distance. Distance Education, 29, 107-118. https://doi.org/10.1080/01587910802004878 
Guerra, L. (2017). Students' Perceptions and Expectations of Native and Non-Native Speaking Teachers. In J. D. D. Agudo (Ed.), Native and Non-Native Teachers in English Language Classrooms (pp. 183-205). Berlin, Boston, MA: Walter de Gruyter Inc. https://doi.org/10.1515/9781501504143-010

Hampel, R., \& Stickler, U. (2012). The Use of Videoconferencing to Support Multimodal Interaction in an Online Language Classroom. ReCALL, 24, 116-137.

https://doi.org/10.1017/S095834401200002X

Hirotani, M., Matsumoto, K., \& Fukuda, A. (2012). Longitudinal Study on Fluency among Novice Learners of Japanese. 2012 EUROCALL Conference Proceedings: Using, Learning, Knowing: EUROCALL, Gothernberg, 22-25 August 2012, 129-134.

Horwitz, E. K., Horwitz, M. B., \& Cope, J. (1986). Foreign Language Classroom Anxiety. The Modern Language Journal, 70, 125-132. https://doi.org/10.1111/j.1540-4781.1986.tb05256.x

Kessler, G. (2018). Technology and the Future of Language Teaching. Foreign Language Annals, 51, 205-218. https://doi.org/10.1111/flan.12318

Lasagabaster, D., \& Sierra, J. M. (2005). What Do Students Think about the Pros and Cons of Having a Native Speaker Teacher? In E. Llurda (Ed.), Non-Native Language Teachers (pp. 217-241). Boston, MA: Springer.

https://doi.org/10.1007/0-387-24565-0 12

Levis, J., Sonsaat, S., \& Link, S. (2017). Students' Beliefs about Native and Non-Native Pronunciation Teachers. In J. D. D. Agudo (Ed.), Native and Non-Native Teachers in English Language Classrooms (pp. 205-236). Berlin, Boston, MA: Walter de Gruyter Inc. https://doi.org/10.1515/9781501504143-011

Lu, R., Goodale, T. A., \& Guo, Y. (2014). Impact of Videoconference with Native English Speakers on Chinese EFL Learners' Oral Competence and Self-Confidence. Open Journal of Social Sciences, 2, 54-60. http://dx.doi.org/10.4236/jss.2014.22008

Mahboob, A. (2004). Native or Non-Native: What Do the Students Think? In L. D. Kamhi Stein (Ed.), Learning and Teaching from Experience (pp 1-31). Ann Arbor, MI: University of Michigan Press.

Miskam, N. N., \& Saidalvi, A. (2018). Investigating English Language Speaking Anxiety among Malaysian Undergraduate Learners. Asian Social Science, 15, 1-7.

https://doi.org/10.5539/ass.v15n1p1

Mustafa, E. N. E. (2018). The Impact of YouTube, Skype and WhatsApp in Improving EFL Learners' Speaking Skill. International Journal of Contemporary Applied Researches, 5, 18-31.

Nilayon, N., \& Brahmakasikara, L. (2018). Using Social Network Sites for Language Learning and Video Conferencing Technology to Improve English Speaking Skills: A Case Study of Thai Undergraduate Students. LEARN Journal: Language Education and Acquisition Research Network, 11, 47-63.

Raja, R., \& Nagasubramani, P. C. (2018). Impact of Modern Technology in Education. Journal of Applied and Advanced Research, 3, 33-35.

Rao, S. P. (2019). The Importance of Speaking Skills in English Classrooms. Alford Council of International English \& Literature Journal, 2, 6-18.

Ritzel, D. O. (2010). International Videoconferencing: A Reaction to Burke et al. American Journal of Health Education, 41, 62-64.

https://doi.org/10.1080/19325037.2010.10599128

Spring, R., Kato, F., \& Mori, C. (2019). Factors Associated with Improvement in Oral Fluency when Using Video-Synchronous Mediated Communication with Native Speakers. Foreign Language Annals, 52, 87-100. https://doi.org/10.1111/flan.12381 
Vurdien, R. (2019). Videoconferencing: Developing Students' Communicative Competence. Journal of Foreign Language Education and Technology, 4, 269-298.

Yang, Y. T. C., Gamble, J., \& Tang, S. Y. S. (2012). Voice over Instant Messaging as a Tool for Enhancing the Oral Proficiency and Motivation of English-as-a-Foreign-Language Learners. British Journal of Educational Technology, 43, 448-464.

https://doi.org/10.1111/j.1467-8535.2011.01204.x 